\title{
Impact Of Radical And Incremental Curriculum Changes On Students
}

\author{
Vipin K Agrawal, California State University, Fullerton, USA \\ Vijay K. Agrawal, University of Nebraska at Kearney, USA \\ Donald A. Carpenter, Mesa State College, USA
}

\begin{abstract}
College curricula undergo changes periodically. This case discusses the various change management strategies employed by the faculty of a midwestern university in implementing incremental and radical change in the business school curriculum. It also analyzes the impact of these changes on student perceptions of the course and of the instructor. Our analysis reveals interesting trends in student responses over a seven year span. We find that students initially resist both types of changes, although the resistance is greater in the case of radical changes. Nevertheless, they eventually view both types of changes as adding value to the curriculum. However, the perception of value addition is temporary, lasting longer for radical change (seven semesters) than for incremental change (five semesters). This suggests that updating of curricula is required on an ongoing basis.
\end{abstract}

Keywords: Business Curriculum, Change Management, Incremental and Radical Change

\section{INTRODUCTION}

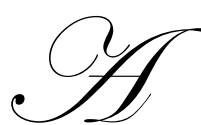

the College of Business at a midwestern university, Fred Weeks ${ }^{1}$, Professor of Management Information Systems (MIS), and Josh Cramer, Assistant Professor of MIS, realized that the undergraduate MIS curricula they offered did not meet the requirements of prospective employers. The dot.com bust in the 1990s and the subsequent sluggish economy had fueled unemployment and competition in the labor markets. To ensure their students remained competitive in the labor markets, in Fall 2001, they embarked on an initiative to redesign the MIS curricula such that it would provide students with a better understanding of the current usage of information technology (IT) in modern businesses. The initiative also aimed to help the college in its accreditation from the North Central Association (NCA) of colleges and schools and the Association to Advance Collegiate Schools of Business (AACSB).

Fred and Josh realized that the curriculum redesign would require both incremental and radical changes to the MIS courses they taught. While they had the full support of the administration and the faculty, Fred and Josh initially encountered significant resistance from students, particularly to the radical changes. To overcome this resistance, they used a systematic, three-pronged approach consisting of change management and project management strategies and support from top leadership.

In response to the changing environment in which businesses operate, business school curriculum, including the MIS curriculum, would continue to undergo both similar changes in the future. To ensure that these future curriculum changes are implemented successfully, Fred and Josh asked themselves two questions. First, what lessons have we learned from the current experience? Second, how can we improve the implementation of future changes?

\section{THE MID-WESTERN UNIVERSITY}

The university was established in 1903 as a state normal school. After progressing through phases as a teachers' college and a state college, it was granted university status in 1991 and became one of the campuses in the 
state university system. It is the only university in the state to draw students from all 93 state counties. In 2001, the university's annual budget was between $\$ 50$ million and $\$ 75$ million, with an enrollment of approximately 6,400 students. Of these, $57.5 \%$ were women. In terms of ethnicity, the student body was predominantly white (87.66\%). In addition, nearly $5 \%$ of the student body consisted of foreigners and $1.5 \%$ were Hispanic/Latino. About $1 \%$ of the student body comprised Black/African-American (0.62\%), Indigenous (0.22\%), and Asian (0.25\%). Since 2001, while the gender ratio has remained fairly constant, the percentage of non-white (including international) students has almost doubled.

Most students attending the university are the first generation from their families to attend college. Furthermore, a vast majority of the students share similar demographics in that they are predominately from rural areas and come from families involved in farming/agriculture, the dominant industry in the state. The pervasiveness of agricultural influence in the typical student's background yields an interesting phenomenon: many of the students were moving from an agro-industrial culture to the computer-communication age. Consequently, most incoming business school students possessed very limited familiarity with computers. For example, in 2004, less than $40 \%$ of these students demonstrated beginner-level proficiency in Microsoft Excel.

\section{COLLEGE OF BUSINESS (CB)}

The CB, which was accredited by the AACSB in April 2006, had an enrolment of 1,543 in 2001 and 1,386 in 2007. The CB has four academic departments: (1) management, (2) marketing \& management information systems, (3) accounting \& finance, and (4) economics \& business administration/education. These departments offer a total of 14 programs of study for students pursuing a bachelor's degree and one program for a master's degree. Each undergraduate business school student is required to complete 36 credit hours of business core classes and 21 hours of course work of his/her major (27 hours for accounting). In addition, undergraduate students from other colleges within the university can get a degree with a minor in one of the business functional areas by completing 24 hours of course work in that area.

In response to the changing business environment, business school curricula in the U.S. and abroad have undergone periodic updating. For example, a growing number of business schools are now teaching the longneglected subject of entrepreneurship. Similarly, to help students relate theory to real world business decisions, professors are inviting entrepreneurs and business leaders to speak to students in class more frequently, as well as asking students to solve real problems brought to them by local and national companies. ${ }^{2}$ Incremental curriculum changes have occurred more frequently than radical ones. This is perhaps because incremental changes can be made without formal institutional permission, whereas radical changes often require approval of the department, college, and university curriculum committees.

The CB curriculum of the mid-western university has also undergone several improvements over the past decade. For example, students in marketing research and accounting courses have been assigned projects to solve real business problems. Further, to remove IT-related deficiencies in the core business curricula shared by all emphasis areas, a Principles of MIS course was added to the core curriculum.

\section{CHANGES TO THE UNDERGRADUATE MIS CURRICULUM}

When Fred joined the MIS unit in 2000, he found that the undergraduate MIS curriculum of the CB reflected the standards set by the computer information systems (CIS) model of the early 1980s. The focus of this curriculum was to help students achieve proficiency in programming skills. However, Fred realized that with the dot.com bust and the sluggish economy, students also needed to gain an understanding of the actual usage of IT in modern businesses in order to be competitive in the labor market. In this regard, he recognized the need for integrating IT throughout the core business curriculum. His views were reinforced in 2003, when one of the standards adopted by the AACSB for business school accreditation ${ }^{3}$ called for the use of information technologies in business curriculum as "they influence the structure and processes of organizations and economies, and as they influence the roles and techniques of management." 
Fred began laying the groundwork for redesigning the curriculum by developing the Model Universal Enterprise Information Structure (MUEIS) database. ${ }^{4}$ This database essentially contains numerous tables for accounting, marketing, manufacturing, management, and human resource applications. For example, one set of tables contains the relevant personal and wage rate information of employees used by the payroll department of a typical company.

In Fall 2001, Fred and Josh (who had just joined the MIS unit as a faculty member) prepared a formal proposal to redesign the MIS curriculum using the MUEIS database. The proposal called for changes to the curricula of both the introductory and advanced MIS courses. The proposal was accepted and the changes were implemented in the Spring 2002 semester. The relevant stakeholders affected by these changes included the faculty, the students, the users, the sponsors (donors funding the project), and the university/CB. While there was support for these changes among faculty, users, donors, and the university, there was considerable resistance from the students. Hence, the successful implementation of these changes arguably relies upon overcoming this resistance.

\section{CHANGES IN THE INTRODUCTORY MIS COURSE: INCREMENATAL CHANGE}

Description of Change: Prior to Spring 2002, to meet course requirements, students in the business computer application class (an introductory MIS course) were assigned a project that involved developing fictitious applications using Microsoft PowerPoint. In Fall 2002 the curriculum was changed, and students were now expected to develop realistic applications for users in the university departments and local businesses (both profit and nonprofit) in the community. As part of the project, students were also expected to maintain ongoing interaction with the users and to use PowerPoint, Excel, and Access.

Nature of Change: The project constituted only $15-20 \%$ of the course grade and could be completed in a few weeks. The rest of the course content remained the same, except for an upgradation of MS Office Suite from MS Office 1998 to MS Office 2003. Since the magnitude of change is small and affects only a small part of the course requirement, this change in curriculum can be considered incremental in nature.

Resistance to Change: Most of the students had previously been exposed only to mechanical learning. They had no group assignments and consequently their grades were dependent on individual efforts. Moreover, since the projects were fictitious, the need to interact with users did not arise. However, the requirements of working on real-life projects were significantly different. They were required to work in groups and develop applications that evolved iteratively through ongoing interaction with users. Not surprisingly, there was resistance among the students to this change.

In addition, there were numerous problems in handling real-life projects. For example, the outcome of the project depended on quick response from user groups, extensive coordination between the students and the users, identification of suitable tools to meet user requirements, and delivering functional applications to the users within a limited time frame. Furthermore, user groups that were not IT literate tended to change the project requirements as they learned more about how IT tools could help them perform tasks more effectively and efficiently. This trial and error approach further intensified resistance amongst the students.

The resistance to change was not uniform amongst the students. It varied based on their age, work experience, level of exposure to technology, whether they were pursuing a business degree, and whether the course was a part of their general studies or core curriculum.

Implementation of Change: To ensure the successful implementation of this curriculum change, Fred and Josh used change management (motivational tools) and project management strategies. In doing so, they relied upon the expertise obtained from their prior work as consultants and managing project development for various companies. To ensure students had the required technical skills to complete the project, they were assigned extensive homework. Furthermore, to motivate students to learn the required skills and turn in high-quality projects, they were awarded extra credit for completing additional homework problems and developing a project with additional technical features. 
For successful interaction with students, the user groups attended classes covering the applications necessary to complete their project. In addition, they were available to students, during and after class, while their projects were being developed. Students also visited the users' sites and offered suggestions that, upon user acceptance, were incorporated into the applications.

Fred and Josh were concerned about their lack of experience in implementing real-life projects in a classroom setting. To mitigate this problem, in Spring 2002 (one semester prior to the curriculum change), Josh, under Fred's supervision, undertook two pilot projects, one at the Christian Heritage ${ }^{5}$ and the other at the University's Dual Career Program. For the Christian Heritage project, two groups were asked to develop a PowerPoint presentation that was to be used in their training programs. For the Dual Career Program project, one group was asked to develop a database with a user interface for keeping information about employees' spouses. This information was to be used to find jobs for the spouses. Both of these projects were successful. In fact, the project developed for the Christian Heritage is still being used today.

The experience on these pilot projects enabled Fred and Josh to further refine their change management and project management strategies. More specifically, they realized that in order to reduce the complications arising from the lack of IT knowledge on the part of the users, they needed to meet with the user groups and develop detailed specifications for each project before the semester began.

Impact of Change: Since Fall 2002, students have completed many real-life projects. In each instance, the users have been extremely pleased with the final product. One of the user organizations even received the state's First Lady's Community Service Award for their accomplishments using the students' product.

To evaluate the effectiveness of the curriculum change and the project and change management strategies they employed, Fred and Josh surveyed students each semester from Fall 2001 (prior to implementation of change) to Spring 2007. A total of 341 students participated in this survey. Feedback from students indicated the following:

- This course was required in their major area of study for approximately $80 \%$ of the students and was a general studies course for approximately $50 \%$ of the students. This distribution in student profile remained fairly constant during the entire period of the study.

- Students reported that the requirement of working on real-life projects stimulated their interest in the course and enhanced their grade expectations.

- Student perceptions of course difficulty and the time spent to complete the coursework remained unchanged following the curriculum change

- During the first two semesters following the change, students reported an increase in the level of motivation of other students. The level then remained the same between Spring 2002 and Fall 2005. Thereafter (Spring 2006 onwards), this level reduced marginally.

- $\quad$ Students' actual learning from the course marginally exceeded their anticipated learning during the entire period of the study. The level of anticipated and actual learning followed similar trends. Students reported an increase in both in Spring 2002 and in Fall 2002. There was no further change in the levels of their learning in the following three semesters. However, from Spring 2005 onwards, the level of learning has been declining gradually.

- $\quad$ Group dynamics helped increase the level of motivation and learning of students with lower skills and of students for whom the course was a general studies course.

\section{CHANGES IN ADVANCED MIS COURSES: RADICAL CHANGE}

Description of Change: Two sequence courses in the MIS curriculum are the Systems Analysis and Design I (SAAD-I) and Systems Analysis and Design II (SAAD-II), the latter being a capstone course. SAAD-I is essentially a theory course which also introduces a project that students are required to complete in the SAAD-II course. Prior to Spring 2002, the project requirements were such that students only designed software for free-standing applications (modules). While these designs were related to real-life applications, students had minimal interaction with the users (university departments, for-profit organizations, and non-profit organizations in the community) and identified most of the requirements through self-study. Furthermore, since students were not required to code their 
software and test it using actual data, design errors were difficult to identify. Additionally, students did not learn how these free-standing modules influenced each other in a fully integrated application.

In Spring 2002, Fred and Josh changed the SAAD-I and SAAD-II curricula to remove these deficiencies. Students were now expected to design, code, and test integrated Web-based interface modules of business applications using the MUEIS database. ${ }^{6}$ These modules were expected to take several semesters to complete and once completed, they were to be used by students in other functional classes (accounting, marketing, human resource management etc.). For example, one module developed was inventory for use by students in the financial accounting and manufacturing courses to enter transactions pertaining to receipt or issue of raw materials, work-inprogress, or finished goods. The transactions then update the existing data in the MUEIS database and instantaneously display their effect on the various accounting statements and subsidiary ledgers.

The users of this project included the students who would use the application modules in their classes, and the faculty who would implement these in their various classes. The modules were to be implemented gradually over a number of semesters, starting with introductory accounting courses, and expanding to marketing and other courses to demonstrate product flexibility. Hence, accounting and marketing faculty and students (i.e., the users) actively participated in designing these modules. The users attended a number of SAAD-I and SAAD-II classes and were available to the students after class. Thus, there was ongoing interaction between the SAAD-I and SAAD-II students and the users.

To successfully complete the project, students needed knowledge of the Active Server Page (ASP) software and a CASE tool software named Visible Analyst. While the Visible Analyst software was taught in the classroom, students were required to learn the ASP software on their own.

Nature of Change: The projects represented approximately $80 \%$ of the SAAD-II course grade and ran for almost the entire semester. However, unlike previous requirements that simply involved the development of systems documentation of free-standing applications, students were now expected to analyze, design, program, and test live modules that could be used in other business classes. Given that the projects were larger, more complex in nature, and focused on integrated learning, these MIS curricular changes in the capstone course can be considered radical in nature.

Resistance to Change: This radical change in the curriculum created a significant amount of resistance amongst the students for several reasons. First, they saw little value-added from this curriculum change. Second, they were required to learn new development tools such as ASP and Visible Analyst. Third, students were now required to not only design but also code and test integrated, Web-based interface modules of business applications. These additional tasks required a higher motivation level, more time, and a greater expertise.

Finally, the heterogeneity in their background was also a contributing factor to the overall resistance in the class. When the change was implemented (Spring 2002), about two-fifths of the students in the class were majoring in MIS and had completed many business courses. The remaining students were majoring in other areas and had little or no business background, even though SAAD-I and SAAD-II were required courses in their program of study. While a large proportion of the MIS majors resisted this change, not surprisingly, an even greater proportion of non-MIS majors were unhappy.

Implementation of Change: To overcome student resistance, Fred and Josh used a systematic, three-pronged approach consisting of change management and project management strategies and support from top leadership. In Spring 2002, they gave students three options to meet course requirements: (1) complete the project as per the new curriculum and receive extra credit of 30\%, (2) complete the project along the lines of the old curriculum (i.e., prior to Spring 2002) and appear for a final non-comprehensive exam, or (3) take a comprehensive final examination. Although all students opted for the first option, a large number of them did not visit the accounting users to get systems specifications. This lack of coordination with the users disrupted the working of their entire team and interfered with the development of the modules, thereby threatening the successful implementation of changes. 
In response, students were offered an opportunity for extra credit on assignments, tests, and group projects/presentations along with help from a systems administrator, IT services staff, graduate students, and an undergraduate student who had been involved in earlier design aspects of the project. Despite all this support, a large number of students approached the college Dean, urging discontinuation of the project and reversing the changes to the MIS curriculum. However, the college leadership remained firm in the belief that these changes were necessary to provide a high-quality education and turned down their request.

As a result of this support, student resistance started declining in Fall 2002. In addition, the enrollment of non-MIS majors declined because SAAD-I and SAAD-II courses were no longer required in their major. This increased homogeneity made it easier for Fred and Josh to implement the various change strategies.

In Spring 2003, students were still provided opportunities for extra credit and programming help from Campus IT Service staff members and graduate assistants. However, taking advantage of declining resistance, Fred and Josh no longer offered the three options from Spring 2002 to the students; instead all students were required to complete the project as per the new curriculum. By this time, Fred and Josh found that students were involved fully in the development efforts and interacted with the user groups. However, there were still complaints about the ASP programming language used in the project; thus, in Fall 2003, Fred and Josh introduced the programming language in the MIS curriculum. Furthermore, by this time, some project planning problems (such as task coordination etc.) had been eliminated. Consequently, from Fall 2003 onwards, resistance to the curriculum change had disappeared.

Impact of Change: Fred and Josh had initially undertaken the design and development of six modules (additional modules were planned following completion of these six). However, due to student resistance, only one module had been fully completed in Spring 2002. As resistance declined, work on the remaining five modules progressed satisfactorily. By Spring 2007, the remaining modules were almost complete, and users found the project results extremely satisfactory.

To evaluate the effectiveness of the curriculum change and the various strategies they had employed, Fred and Josh again surveyed students each semester from Fall 2001 (prior to implementation of change) to Spring 2007. A total of 130 students participated in this survey. There were several significant findings:

- $\quad$ For most of the students, these courses were required in their major area of study and did not belong to general studies.

- $\quad$ Student grade expectations at the end of semester were higher than those at the beginning of the semester during the entire period of the study. Additionally, the difference between the two remained constant in the initial period, tapering off slightly during the latter part of the study (from Fall 2003).

- $\quad$ Students report that both the perceived difficulty of and the average amount of time spent on the course in the second year were significantly higher than in the first year. Both these metrics continued to increase over the remainder of the study, albeit at a more gradual pace.

- $\quad$ Students perceived a decline in the motivation levels of other students in Spring 2002. This trend was reversed in Fall 2002, and student perceptions of the motivation levels of other students continued to increase each semester until Fall 2005. However, the trend again reversed in Spring 2006.

- $\quad$ Both anticipated and actual learning declined in Spring 2002. However, in each semester from Fall 2002 to Fall 2005, students reported an increase in both anticipated and actual learning. Finally, from Spring 2006 onwards, both anticipated and actual learning declined.

\section{IMPLEMENTING FUTURE CURRICULUM CHANGES}

Changes to the MIS curriculum initiated in Spring 2002 have now been successfully implemented. Fred and Josh realize that trends such as globalization and outsourcing have resulted in a turbulent and often unpredictable environment in which businesses operate. Business school curriculum, including the MIS curriculum, would therefore continue to undergo both radical and incremental changes in the future. To ensure that future changes are also implemented successfully, Fred and Josh want to determine how to improve their strategies for implementing change and decided to focus on three main goals. 
The first goal is to minimize the adverse reaction among students due to the implementation of changes in the curriculum. When implementing these changes in 2001, they had expected to overcome student resistance within seven to ten days for the incremental change and a couple of months for the radical change. However, it actually took longer, particularly in the case of the radical change. They are concerned that such a prolonged recovery time would lead to a substantial increase in the students' dissatisfaction with both the instructor and the curriculum change. This would adversely affect the reputation and the enrollment of the college, which in turn would lead to a loss of support from the administrators for future changes in business curriculum.

The second goal is to eliminate flaws in project management that result from inaccurate time estimation, lack of user knowledge of the application they intend to develop with students, lack of instructor knowledge of the applications, and communication gaps between students and users, and between students and instructor. They are also concerned that poor project management may result in failure to complete the project or lead to delivery of applications with limited functionality. In turn, this would reduce support for the curriculum change among the students, faculty members, and more importantly, the users. The third goal is to increase the value-addition from these changes to both the students and the users. Fred and Josh believe that the longer students viewed curriculum changes as adding value to their learning, the easier it would be for the administration to support faculty in future curriculum changes.

To accomplish these goals, Fred and Josh have decided to focus on the objectives listed in Table 1.

Table 1: Objectives

\begin{tabular}{|c|c|}
\hline \multicolumn{2}{|c|}{} \\
\hline Resistance to change - minimization objective \\
\hline$\bullet \quad$ Minimize the time of recovery to normal \\
\hline$\bullet \quad$ Minimize the adverse reaction among students \\
\hline Flaws in project management - minimization objective \\
\hline$\bullet \quad$ Minimize the unknowns during project execution \\
\hline$\bullet \quad$ Minimize users' lack of knowledge during project execution \\
\hline$\bullet$ & Minimize the gestation period of learning by users \\
\hline$\bullet$ & Minimize the gestation period of learning by students \\
\hline$\bullet$ & Minimize the gestation period of learning by instructor \\
\hline Value addition to core curriculum - maximization objective \\
\hline$\bullet \quad$ Maximize the period over which students consider the curriculum change as adding value \\
\hline$\bullet$ & Maximize user satisfaction level about the quality of product \\
\hline
\end{tabular}

These objectives must be carried out within the boundaries of several constraints. First, any change should not increase inefficiencies in resource allocation within the university. Second, any change would have to be feasible for the affected stakeholders, i.e., students, instructors, users, support staff, and college officials. Third, any change strategy should account for student diversity and ensure fair treatment to all.

\section{QUESTIONS}

This case focuses on the following interrelated questions:

(1) Should Fred and Josh expect resistance to future curriculum changes?

(2) What strategies are recommended for handling resistance to change? Evaluate the effectiveness of and suggest improvement to the strategies used by Fred and Josh to overcome resistance to curriculum change.

(3) How do organizational members (here students) experience change?

(4) How long did students view incremental and radical changes as adding value to the curriculum? Why is the value addition temporary? 
(5) What are the differences in student profile in introductory and advanced level courses that would affect the resistance to change and the change management strategies to be used? What recommendations can be provided to instructors contemplating curriculum change?

(6) What procedures/policies should be followed by faculty members for effective and efficient project management?

\section{NOTES}

${ }^{1}$ In the interest of anonymity, the names of the professors have been changed.

${ }^{2}$ To improve the curriculum at Pepperdine University, students have been attempting to solve real marketing problems brought to the school by companies such as Coca-Cola, Disney, and Raytheon [New Graduation Skills. (2007, May 12). The Economist, 383(8528), 75-76].

${ }^{3}$ AACSB International (Adopted April, 2003, Revised January 31, 2007). Eligibility procedures and standards for business accreditation. The Association to Advance Collegiate Schools of Business.

${ }^{4}$ Additional details about the database, while not relevant for this case, can be found in Carpenter (1992) [ Development of an information requirements determination methodology: Utilization of normative analysis from a Universal Enterprise Information Model. Ann Arbor: University Microfilms International Dissertation Service] and Carpenter (1994) [Casebook for McFadden, F., \& Hoffer, J., Modern Database Management, 4th ed. Redwood City, CA: Benjamin-Cummings Publishing].

${ }^{5}$ Christian Heritage is a non-profit, group home organization for abused and neglected youth ages 12-18.

${ }^{6}$ The development of the modules used phases of system analysis and design (Whitten, et. al., 2007).

\section{TEACHING NOTE}

\section{Case Overview}

In 2001, Fred Weeks and Josh Cramer presented a proposal that called for changes in the undergraduate MIS curricula of the College of Business (CB) at a small midwestern U.S. university. The proposed changes to the introductory course were incremental in nature, while those for the advanced course were radical in nature. To implement these changes, Josh, under the supervision of Fred, incorporated integrated projects in both courses. The relevant stakeholders affected by these changes (Pearlson \& Saunders, 2004, p. 265) included the project manager (faculty), the customers (students), the users (university departments, for-profit organizations, and non-profit organizations in the community), the sponsors (e.g., donors funding the project), and the performing organization (university/CB). While there was support for these changes among faculty, users, donors, and the university, initially there was considerable resistance from the students. Hence, the successful implementation of these changes arguably relied upon overcoming this resistance.

Fred and Josh employed various strategies to overcome student resistance. To overcome resistance to the incremental and radical curriculum changes, they used appropriate project management and change management tools such as incentives in terms of extra course credits (Agrawal and Carpenter, 2005). In the case of the radical change, where the resistance was more severe, they also relied upon the support from top leadership.

The changes to the MIS curriculum have now been successfully implemented. Fred and Josh realized that in response to the changing environment, business school curriculum, including the MIS curriculum, would continue to undergo both radical and incremental changes in the future. Fred and Josh wanted to understand the lessons learned from their experience and improve upon the strategies to overcome student resistance to future curriculum changes. In this regard, they studied the trends in student survey responses each semester between Fall 2001 (prior to implementation of change) and Spring 2007. Students participating in the survey were representative of the student body at the CB of the midwestern U.S. university. Therefore, Fred and Josh believed the results could be generalized for curriculum changes in all CB courses. The key findings of the survey were as follows. 


\begin{tabular}{||l|l|l||}
\hline \multicolumn{1}{||}{ Survey Item } & \multicolumn{1}{|c||}{$\begin{array}{c}\text { Incremental Change } \\
\text { (Course: MIS) }\end{array}$} & \multicolumn{1}{c||}{$\begin{array}{c}\text { Radical Change } \\
\text { (Courses: SAAD-I, SAAD-II) }\end{array}$} \\
\hline Student distribution & $\begin{array}{l}\text { Required course in major area of study for } \\
80 \% \text { students; general studies course for } \\
50 \% \text { students. }\end{array}$ & $\begin{array}{l}\text { Required course in major area of study for } \\
\text { most students. }\end{array}$ \\
\hline Student grade expectations & Enhanced throughout the period of study. & $\begin{array}{l}\text { Higher at the end of the semester than at } \\
\text { the beginning; difference remained } \\
\text { constant initially (two semesters), and then } \\
\text { tapered off slightly. }\end{array}$ \\
\hline $\begin{array}{l}\text { Student perception of course } \\
\text { difficulty and time spent to } \\
\text { complete coursework }\end{array}$ & No change. & $\begin{array}{l}\text { Significantly higher in semesters 3 and 4 } \\
\text { than in semesters 1 and 2. Continued to } \\
\text { increase throughout period of study, } \\
\text { although at a slower rate. }\end{array}$ \\
\hline $\begin{array}{l}\text { Other students' level of } \\
\text { motivation }\end{array}$ & $\begin{array}{l}\text { Increased initially (two semesters), then } \\
\text { remained constant (eight semesters), then } \\
\text { declined marginally. }\end{array}$ & $\begin{array}{l}\text { Declined initially (one semester), then } \\
\text { increased (eight semesters), then started } \\
\text { declining again. }\end{array}$ \\
\hline $\begin{array}{l}\text { Actual and anticipated learning } \\
\text { from course }\end{array}$ & $\begin{array}{l}\text { Increased initially (two semesters), then } \\
\text { remained constant (three semesters), then } \\
\text { declined gradually. Actual learning exceeded } \\
\text { anticipated learning. }\end{array}$ & $\begin{array}{l}\text { Declined initially (one semester), then } \\
\text { started increasing (eight semesters), then } \\
\text { started declining again. }\end{array}$ \\
\hline $\begin{array}{l}\text { Number of participants in } \\
\text { survey }\end{array}$ & 341 & 130 \\
\hline \hline
\end{tabular}

\section{Intended Audience and Value of the Case}

This case is appropriate for an introductory organizational behavior course, as well as more advanced courses in corporate strategy, project management, and information systems strategy and management. The learning objectives for students in each type of course are suggested in the next section. The case is particularly well suited in the topic areas of change management, organizational design, and project management.

The case has several valuable aspects. First, it illustrates how change can be managed. Research suggests that for survival and growth, organizations need to continuously transform themselves through incremental and radical changes (Garud, Kumarswamy, and Sambamurthy, 2006). This is particularly true in the current turbulent and uncertain business environment. Therefore, it is important for organizations to learn how to manage change. Second, it discusses how heterogeneity amongst group members affects the implementation of changes. Third, it illustrates how appropriate project management strategies can eliminate most of the difficulties arising in real-life projects/live environments and aid in successful completion of the tasks. Finally, what makes the case both appealing and challenging is that although there is quite a bit of research that discusses how change should be managed in business organizations, little prior research exists to guide instructors in a college environment. This case provides guidance as to how faculty can overcome student resistance to curriculum changes.

\section{Learning Objectives}

After discussing this case, students should be able to accomplish the following objectives:

- $\quad$ Introductory organizational behavior course

- Describe how incremental and radical episodic changes can be implemented, with an emphasis on Lewin's (1947) three-stage approach to implement change.

- Understand the need for incentives for incremental change and top leadership support for radical change.

- Understand how an individual experiences change.

$\circ$ Describe the relationship between group diversity and resistance to change.

- Understand the need to address multiple stakeholder objectives in change management strategies. 
- $\quad$ Project management course

$\circ$ Understand the project manager's role and the need for fast paced manager and user group learning for adequate and timely guidance to individuals implementing the change.

- Describe the benefits of developing feasible integrated projects.

- Understand criteria for forming teams such that less skilled/less motivated individuals benefit from more skilled/more motivated individuals through group interactions.

- $\quad$ Advanced courses in corporate strategy course

- Describe the role of technology as an environmental element driving changes in the organizational design.

- Understand the supporting role of technology in developing organizational design.

- Understand the need to address multiple stakeholder objectives in change management strategies.

- $\quad$ Information systems strategy and management course

- Understand how IT infrastructure/architecture should be implemented in an environment where customers react adversely because they do not completely understand the value-added from the change.

- Understand the need to address multiple stakeholder objectives in change management strategies.

\section{$\underline{\text { Responses to Discussion Items }}$}

(1) Should Fred and Josh expect resistance to future curriculum changes?

There are two types of organizational changes - continuous changes and episodic changes (Weick and Quinn, 1999). Continuous changes are small continuous adjustments driven by alert reactions to daily contingencies. These changes cumulate over time and create substantial change. Episodic changes tend to be infrequent and intentional. These occur when organizations fail to adapt to a changing environment and consequently, have moved away from their equilibrium conditions. In this present context, the changes in the MIS curriculum of the business school (organization) were necessitated as a result of the divergence between the focus of the curriculum (help achieve students achieve programming proficiency) and the business needs (environment). In other words, the changes described in this case are episodic in nature.

Resistance to episodic change, such as curriculum changes, should be expected if the change is initially perceived as undesirable and stressful. In this present context students resisted the change because both these conditions existed. More specifically, the undergraduate students came from an agro-industrial background with little or no work experience. Consequently, they were unaware of the current requirement of businesses and believed that the curriculum changes placed an unnecessary burden on their time. Further, they were placed outside their comfort zone and did not have confidence in their ability to handle the new tasks (in this case, real-life projects), particularly because these tasks had to be completed within a limited time-frame.

What strategies are recommended for handling resistance to change? Evaluate the effectiveness of and suggest improvement to the strategies used by Fred and Josh to overcome resistance to curriculum change.

Lewin (1947) argues that to successfully implement change, three steps must be followed: unfreezing, moving, and refreezing. Unfreezing is the process of ceasing old habits and creating a climate receptive to change. Moving is the process of learning new work methods, behaviors, and systems, while refreezing involves reinforcing the changes in order to make the new processes acceptable and habitual.

Building on Lewin's work, Kotter (1995) recommended that eight steps should be followed to implement change: (a) establishing a sense of urgency by showing that the status quo is much more undesirable than the unknown, (b) forming a powerful coalition of individuals who embrace the need for change and can rally others to support the effort; (c) creating a vision to direct the change effort and develop a strategy to accomplish the desired end-result; (d) communicating the change vision; (e) empowering a broad base of people to act on the vision by removing or changing systems and structures that undermine the vision; (f) planning for and creating short-term wins; $(\mathrm{g})$ consolidating gains and changing other structures, systems, procedures, and policies that undermine the vision; and (h) institutionalizing the new approaches in the organizational culture by articulating the connection 
between the change effort and organizational success. The first four steps of Kotter's model correspond to the unfreezing process, the next three to the moving process, and the last step to the refreezing process.

In the present context, consistent with the recommendations of Lewin and Kotter, Fred and Josh used various strategies to overcome resistance to change. First, weaker students were purposely combined with bright and motivated students, allowing group dynamics to play an important role by uplifting weaker students and completing the project requirements. At the same time, the motivated students helped nullify resistance from the unmotivated students. Second, in order to reduce the complications arising from the lack of IT knowledge on the part of the users, Fred and Josh met with the user groups and developed detailed specifications of each project before the semester began. Third, students were provided incentives in terms of extra credits.

While these strategies were sufficient to overcome resistance to the incremental change, Fred and Josh used additional strategies to manage the greater resistance involved with radical change. First, they ensured that they had support of the top leadership before implementing the curriculum change. Second, to reduce students' anxiety, they arranged for help from a systems administrator, IT services staff, graduate students, and an undergraduate student who had been involved in earlier design aspects of the project. Finally, Fred and Josh knew that once a significant majority of students understood the value-addition to the curriculum from the radical change, the positive feedback received by students who took the course in future semesters would ensure the substantial mitigation of student resistance in the future. Therefore, they no longer offered the three options from Spring 2002 to the students; instead, all students were required to complete the project as per the new curriculum.

These strategies helped mitigate the resistance in about one semester for incremental change, and in three semesters (Spring 2002 to Spring 2003) for radical change. When implementing these changes, they had expected to overcome student resistance much quicker. Such a prolonged recovery time may result in a loss of administrative support for future changes in business curriculum. Thus, while they were successful in implementing the change, the recovery time was longer than optimal.

One potential way for reducing the recovery time is, as Kotter recommends, by demonstrating that the status quo is much more undesirable than the unknown. They can do so by inviting, at the beginning of the semester, a panel of business leaders and recent alumni to discuss the existing business environment and the divergence between focus of the curriculum and the needs of businesses.

How do organizational members (here students) experience change?

As change unfolds, organizational members undergo either a positive cycle or a negative one (Connor, 1992). A positive cycle occurs when a change is perceived to be desirable. Under this cycle, organizational members go through five phases (Mecca 2004): a) uninformed optimism where it appears all major obstacles have been indentified or planned for, b) informed pessimism, where problems start to surface and morale drops, c) hopeful realism, when they start to perceive the change differently and, based on solid testing, develop a new confidence in their ability to handle future problems, d) informed optimism where confidence grows in self and the change, and e) rewarding completion.

A negative cycle occurs, as is the case here, when the change is perceived to be undesirable. This cycle consists of seven stages: immobilization, denial, anger, bargaining, depression, testing, and acceptance. Immobilization indicates the inability to move forward and is considered a shock to the system. This is an active emotional response and therefore difficult to control. This stage was made worse in the present context because students assumed that the new initiative would fade away like previous ones (denial). However, when the faculty and top leadership did not support the students, the second peak emotional response of anger resulted, and in many groups, students did not cooperate with other members, and even avoided meeting with user groups. This brought them into the bargaining stage where all the groups were offered three choices, including the one they demanded. Students reluctantly accepted the change because the conditions attached to their preferred choice made it unattractive. The resentful students then reached the depression stage and started to work on the changed agenda. As the groups began to find the new assignment doable (testing), they adjusted to the new situation, and finally, acceptance occurred in the form of a positive emotional response to the change. 
(4) How long did students view incremental and radical changes as adding value to the curriculum? Why is the value addition temporary?

Students considered incremental change as adding value to the curriculum for only five or six semesters, while radical change was considered as adding value for only seven semesters. As more and more business schools started integrating IT throughout the core business curriculum, textbooks relating to various functional areas were modified and CDs were included to illustrate how IT concepts and tools can help make more efficient and effective decisions relating to the respective areas. Students in the MIS course therefore began to expect a curriculum where they would have to develop real-life applications. Not surprisingly, their perception of the value added by the curriculum changes (as with any curriculum change or, in fact, any innovation) lasted for a limited time.

What are the differences in student profile in introductory and advanced level courses that would affect the resistance to change and the change management strategies to be used? What recommendations can be provided to instructors contemplating curriculum change?

The introductory MIS course at the CB, during the period of study, was a required course in their major for approximately $80 \%$ of the students and a general study course for approximately $50 \%$ of the students. Such heterogeneity in student profile is common in introductory classes. Further, students are less focused on the subject and their career and consequently, are less motivated. These characteristics not only increase the resistance to change, but also make implementing change more complex.

In Fall 2001-Spring 2002, a little over 50\% of the students taking the advanced MIS course at the CB were non-MIS majors. However, in subsequent years, the enrollment of non-MIS majors declined substantially because these courses were no longer required in their major. This homogeneity in student profile is common in advanced level courses. Further these students are highly focused on the subject and their career. This reduces resistance to change and makes the implementation of change less complex.

Therefore, it is recommended that, (a) if changes are to be implemented in introductory classes, they should be incremental in nature, (b) radical changes should be implemented in advance courses, and (c) at intermediate levels, a hybrid approach would probably work best.

(6) What procedures/policies should be followed by faculty members for effective and efficient project management?

The user groups and faculty should be well prepared before introducing the projects in the classroom. This preparation involves developing detailed specifications for each project so that once it is introduced, they can focus on just one aspect, that is, ensuring that students receive effective guidance in handling the problems that inevitably arise in real-life projects/live environments. The confidence level of faculty and users will help boost student confidence and eliminate the fear of the unknown, which is likely at the root of a lot of the resistance they exhibit. Furthermore, the instructor should divide students into groups such that each group includes some students who are highly motivated, since they can inspire the others.

\section{Teaching Plan}

This case is probably best used following a discussion of change management in an organizational behavior course. In strategy courses (corporate strategy, and information systems strategy and management), the topic could be covered along with IT enabled transformation, while in a project management course, its most appropriate use would be following a discussion of the project manager's role. In these courses, the case can also be used when discussing the influence of group diversity on the successful implementation of incremental and radical changes.

The class can be divided into groups for the purpose of discussing the case. Each group can be asked to formulate a change management strategy using various motivational tools and project management strategies. Prior to beginning their discussions, it would be useful to remind students that while monetary rewards may provide the required motivation in for-profit organizations, non-monetary rewards are more realistic in non-profit organizations, 
including academic environments. Once the groups have formulated their ideas, they can be asked to work through the discussion questions. Finally, the entire class can attempt to reach a consensus regarding a solution.

\section{$\underline{\text { Research Basis and Epilogue }}$}

This case and teaching note were written to present the problem initially observed in a research study (Carpenter and Agrawal, 2008). The study's original purpose was to find a better method for implementing pedagogical improvements in a college curriculum. This case seeks to determine the levels of study at which incremental and radical changes would be most appropriate, and furthermore, how often new, innovative curriculum changes were needed for students to perceive them as adding value to the course content. We conclude that only incremental changes should be implemented in introductory courses, while radical changes should be implemented at advanced levels. The results suggest that at intermediate levels, a hybrid approach works best. Additionally, students considered incremental changes as adding value to the curriculum from the outset, although the effects lasted only five or six semesters. With regard to radical changes, while students initially resisted them, they eventually (after three semesters) came to appreciate the additional value these changes created. Yet, the effect of radical change lasted only seven semesters. Hence, the implication is that updating of curricula is required on an ongoing basis.

At the point in time described in this case, Fred and Josh were considering other changes to the MIS and CB Curriculum in order that students continuously find value-added in their curriculum and their learning is maximized.

\section{AUTHOR INFORMATION}

Vipin K Agrawal, after receiving his undergraduate degree (in Electronics and Communications Engg.), went to Texas A\&M University for his M.S. (Finance) and the University of Texas at Austin for his PhD (Finance). Since 2003, he has been an Assistant Professor at California State University at Fullerton. In addition, he was Visiting Assistant Professor at the University of Texas at Austin for the 2006-2007 academic year. His research has been published in journals such as The Quarterly Review of Economics and Finance and has been presented at various conferences such as the Financial Management Association and National Decision Sciences Institute.

Donald A. Carpenter is Associate Professor of Computer Information Systems at Mesa State College. He holds a B.S. from Kearney State College, an MBA from the University of Colorado at Colorado Springs, and a Ph.D. from the University of Nebraska-Lincoln. Prior to starting his teaching career, he accumulated ten years experience in the information technology industry. His teaching and research interests are in CIS education, decision support systems, information requirements determination, enterprise resource planning, and meaningfulness of IS work. He has published books, chapters, articles in Journal of Computer Information Systems, Journal of Computer Science Education, International Journal of Decision Support Systems, and dozens of conference proceedings.

Vijay K. Agrawal is an Associate Professor of Management Information Systems in the College of Business and Technology at the University of Nebraska at Kearney. His areas of interest are management information systems, operations management, and accounting. He received his B.S. in mechanical engineering from the University of Indore, MBA from the University of Toledo, and M.S. in computer science from Bowling Green State University. He received his Ph.D. from Jamia Millia Islamia (University of Millia Islamia), New Delhi, India. He has published in Production and Operations Management, National Social Science Journal, Global Journal of Flexible Systems Management, Encyclopedia of Operations Research and Management Science, and others.

\section{REFERENCES}

1. Agrawal, V. K., \& Carpenter, D.A. (2005). IT-enabled transformation of business schools' core curriculum: A longitudinal study on incremental change. Proceedings of the Midwest Decision Science Institute, Toledo, Ohio, April 14-16. 
2. Carpenter, Dnald A. and Agrawal, Vijay K (2008). Infusing information technology into core business curriculum: A Change management project. The Journal of Business Inquiry: Research, Education, \& Application, Vol. 7, Iss. 1, pp. 3-20.

3. Connor, Daryl (1993). Managing at the speed of change. NY:New York, Random House.

4. Garud, Raghu; Kumarswamy, Arun; and Sambamurthy, V. (2006). Emergent by design: Performance and transformation at Infosys Technologies. Organization Science, March-April, Vol. 17, No. 2, pp. 277-286.

5. $\quad$ Kotter, J. (1995). Leading change: Why transformation efforts fail. Harvard Business Review, 73 (2): 59 67.

6. Lewin, K. (1947). Frontiers in group dynamics. Human Relations, 1: 5-41.

7. Mecca, T.W. (2004). Basic concepts of organizations change for administrative leaders, working paper.

8. Pearlson, K. E., \& Saunders, C. S. (2004). Managing and using information systems: A strategic approach, $2^{\text {nd }}$ ed. New York: John Wiley and Sons.

9. Weick, K., \& Quinn, R. (1999) Organizational change and development. Annual Review of Psychology, 50: 361-386. 